\title{
Agricultural Management through Wireless Sensors and Internet of Things
}

\author{
Sridevi Navulur ${ }^{1}$, A. S. C. S. Sastry ${ }^{2}$, M. N. Giri Prasad ${ }^{3}$ \\ ${ }^{1}$ Research Scholar, Electronics and Communication Engineering, Koneru Lakshmiah University \\ ${ }^{2}$ Professor, Electronics and Communication Engineering, Koneru Lakshmiah University \\ ${ }^{3}$ Professor, Electronics and Communication Engineering, Jawaharlal Nehru Technological University
}

\section{Article Info \\ Article history: \\ Received Apr 23, 2017 \\ Revised May 22, 2017 \\ Accepted Jun 15, 2017}

\section{Keyword:}

Agriculture

Android

Automation

Internet of things

Micro controller

Raspberry Pi

Wireless sensors

Remote management

\begin{abstract}
Agriculture plays a significant role in most countries and there is an enoromous need for this industry to become "Smart". The Industry is now moving towards agricultural modernization by using modern smart technologies to find solutions for effective utilization of scarce resources there by meeting the ever increasing consumtion needs of global population. With the advent of Internet of Things and Digital transformation of rural areas, these technologies can be leveraged to remotely monitor soil moisture, crop growth and take preventive measures to detect crop damages and threats. Utilize artificial intelligence based analytics to quickly analyze operational data combined with 3rd party information, such as weather services, expert advises etc., to provide new insights and improved decision making there by enabling farmers to perform "Smart Agriculture". Remote management of agricultural activities and their automation using new technologies is the area of focus for this research activity. A solar powered remote management and automation system for agricultural activities through wireless sensors and Internet of Things comprising, a hardware platform based on Raspberry Pi Micro controller configured to connect with a user device and accessed through the internet network. The data collection unit comprises a set of wireless sensors for sensing agricultural activities and collecting data related to agricultural parameters; the base station unit comprising: a data logger; a server; and a software application for processing, collecting, and sending the data to the user device. The user device ex: mobile, tablet etc. can be connected to an internet network, whereby an application platform (mobile-app) installed in the user device facilitates in displaying a list of wireless sensor collected data using Internet of Things and a set of power buttons. This paper is a study and proposal paper which discusses the factors and studies that lead towards this patent pending invention, AGRIPI.
\end{abstract}

Copyright $\odot 2017$ Institute of Advanced Engineering and Science. All rights reserved.

\section{Corresponding Author:}

Sridevi Navulur,

Research Scholar, Department of Electronics and Communication Engineering,

Koneru Lakshmiah University.

Green Fields, Vaddeswaram, Guntur, Andhra Pradesh, India 522502

Email: sri.lalitha.n@gmail.com

\section{INTRODUCTION}

The 21 st century global population growth which is estimated to reach 9.1 billion by 2050 will pose myriad of challenges and demands for food and livestock. It would require raising overall food production by to $70 \%$ by 2050 . Production in the developing countries would need to almost double. This inferred significant increases in the annual cereal production by almost one billion tones, meat production by over 200 
million tones to a total of 470 million tons in 2050,72 percent of which would be supplied from developing countries.

The world must produce more nutrient and fiber contained food to feed a growing population. In the agriculture depended developing countries like India, China, Brazil etc., the feed stocks playing vital role in over all development. It has been a standard practice for the farmers to be present in person at his/her agriculture site through out the crop life cycle for managing, maintaining and protecting crops. The need for "Smart Agriculture" arises due to this requirement, where $70 \%$ of the farming time is just monitoring and managing but not the actual field work. This research foucesses a proposed platform consisting of Web based Smartphone Applications combined with Wireless sensors.

The research on making the agricultural management "Smart" started with study and review of Wireless Sensor applications in Agriculture, in the field of Animal husbandry, green house, wild life, coal mines etc. In today's world mobiles, have proven to simplify most of our activities. Applying these princples of remote management and portability to the back-bone of World economy - "Agriculture" changes the way the Indian/global farmers perform their farming activities. A system and method is proposed for automation of agricultural activities with the help of these technologies. The system helps the field monitoring activities like water pumping scheduling, plant monitoring, protection from animals and insects etc. to be remotely managed with the help of Mobile sensors and Mobile Apps. A patent is filed for this research and development of software and hardware is in progress.

\subsection{Applications of Sensors}

An important application of sensors in agriculture is in the direct measurement of soil chemistry through tests such as $\mathrm{pH}$, moisture, nutrient content, Humidity, temperature. Soil testing results are important to obtain to get high yield with good quality. ISE (Ion Selective Electrode) and ISEFT (ion-sensitive fieldeffect transistor) sensors have also been used to monitor the uptake of ions by plants. The rate of nutrient uptake is determined by the demand of the plant, which is dependent on the growth rate and on the status of the plant's nutrient content. Ion-selective sensors have been developed to detect a variety of ions. ISE sensors have been developed to monitor nitrogen ions in the soil and crops. Hi-tech systems are in demand to help grow high-performance crops. Researchers are using sensors to match the crops to different soils and weather conditions.

\subsubsection{Sensors in Farming}

The day-to-day farming activities are focused on how to grow plants, kill weeds and pests, identify and correct plant diseases, apply fertilizers, and estimate growth/yield of crops. They involve a handful of tasks which are performed in the field, that is, seeding, weeding, fertilizing, and watering, which are repetitive, mundane, and labor-intensive. Nevertheless, these very tasks are vital and precursory decisionmaking steps prior to actual farming activities and crop cycling to be effective.

1. Disease identification \& Diagnosis

2. Fertilizer Calculator

3. Soil Study

4. Water Study

5. Need of Crop Needs Estimation

6. Analysis of Crop Produce Readiness

7. Identification Temperature and Humidity (for Horticulture crops)

\subsubsection{Sensors in Greenhouses}

The main objective of Greenhouses is to provide the required inputs to plants at the right time in the correct ratio. Sensors are mainly used in a greenhouse system to measure temperature, control temperature, humidity, $\mathrm{CO} 2$, aeration, ventilation, lighting, thermal and solar shading; regulating hot water and steam heating systems, fog and mist prevention to list a few but many more applications are being updated continuously.

\subsubsection{Sensors in Livestock}

The farming industry is an important sector of the global economy with an annual turnover of 100 billion dollars. USA, Canada, Australia, Brazil, Spain, China are major players in farming industries. In livestock farming management, sensors are used to determine the $\mathrm{pH}$ level and the temperature inside a cow's rumen and to monitor important vital signs such as core temperature, heart rate, and blood oxygen levels by tagging RFID (Radio Frequency identification) sensors. 


\subsubsection{Sensors in Wildlife}

The rapid growth of human population in the world impelled by agricultural and industrial growth has led to the conversion of forests into human settlements. Due to this, wild animals face severe shortage of water and food. In Asian countries like India and Bangladesh wild elephants, panthers and lions have often entered villages causing panic to humans. In these conditions sensors are crucially helpful not only in tracking and monitoring the animals which enter villages but also a major necessity in ascertaining animal species and populations.

\subsubsection{Other Applications of Sensors}

Acoustic sensors were developed for identification of soil texture. It functions by measuring the change in noise level due to the interaction of a tool with soil particles. Airflow sensors were used to measure soil air permeability, measure percentage of moisture, identify soil structure and to distinguish different types of soils. Electrochemical sensors play a major role in agricultural fields. These sensors are used to measure the macro and micro nutrients in the soil, salinity and $\mathrm{pH}$. Electromagnetic sensors are used to map electrical conductivity and transient electromagnetic response, identify electrical response, adjust variable rate application in real-time. Other important applications are identification of residual nitrates and organic matter in the soil. Mechanical sensors use a mechanism that penetrates or cuts through the soil and records the force measured by strain gauges or load cells.

Field-programmable gate array (FPGA) based fused smart sensors to measure real-time plant transpiration monitoring using this sensor. Optical sensors are used to predict clay, organic matter and moisture content. Ultrasonic ranging sensors Apple tree canopies are analyzing by this U R sensors. Raman \& F T I.R spectroscopy structural differences of celluloses can be detected by F T I R and Raman Spectroscopy. Reflect metersis specifically used for determination of moisture in oil palm fruits. Optoelectronic sensors are used to detect weed in wide row crops. Eddy covariance sensors helps in quantifying of carbon metabolism of peat lands. Fluorescence-based optical sensor is used for plant constituent assessment, mainly to supervise grape maturation. Acoustic sensor is used for classification of seeds by analyzing their sound absorption spectra. Soft water level-based (SWLB) sensors are used in agriculture catchments to characterize the hydrological behavior SWLB are very helpful sensors.

Optical and microwave sensors are used for characterizing olive grove canopies. LIDAR sensors are used to get dynamic measurement information regarding fruit-tree leaf area and it is combined with GPS to get 3D map. Majorly this sensor are used for estimating biomass in alpine forest. Argos sensor is a satellitebased sensor system which collects, processes and disseminates environmental data from fixed and mobile platforms worldwide. APR Sensors Automatic Packet Reporting System (APRS) is an amateur radio-based system for real time tactical digital communications of information of immediate value in the local area. GIS Sensors A geographic information system or geographical information system sensor is used to capture, store, manipulate, analyze, manage and present all types of spatial or geographical data. Surveillance sensors are used for monitoring the behavior, activities and/or other changing information in animals. Telematics sensors used for telecommunication between two places or two vehicles in the forest. Telemetry sensors are used to collect data from remote or inaccessible points. For example, crocodile or shark movements under water.

\section{THE PROPOSED RESEARCH METHOD - AGRIPI}

The aim of this research work is to invent a mobile based sensor automation system to determine the soil condition (physical and chemical) including humidity, the $\mathrm{pH}$ of soil and water and water levels in the field. A major advantage of this device is the incorporation of various animal / insect sounds as signals. As an example, the vibrations made by elephants entering premises can be received as input signals based on the earth's vibration. The sensor is programmed to imitate the sound of buzzing bees which will not only stop elephants from entering the field but will set off an alarm to alert the monitoring personnel. Similarly, bird scan be warded off from spoiling crops before the harvest by placing sensors that will make suitable sounds to petrify them. To avoid any failure of its function due to power failures and surges, the device is made with solar rechargeable batteries. This device also takes care of switching on or off the watering systems remotely which helps farmers to precisely monitor and set timers for the water pumping systems using the smart app in the mobile device.

IJECE Vol. 7, No. 6, December 2017 : 3492 - 3499 


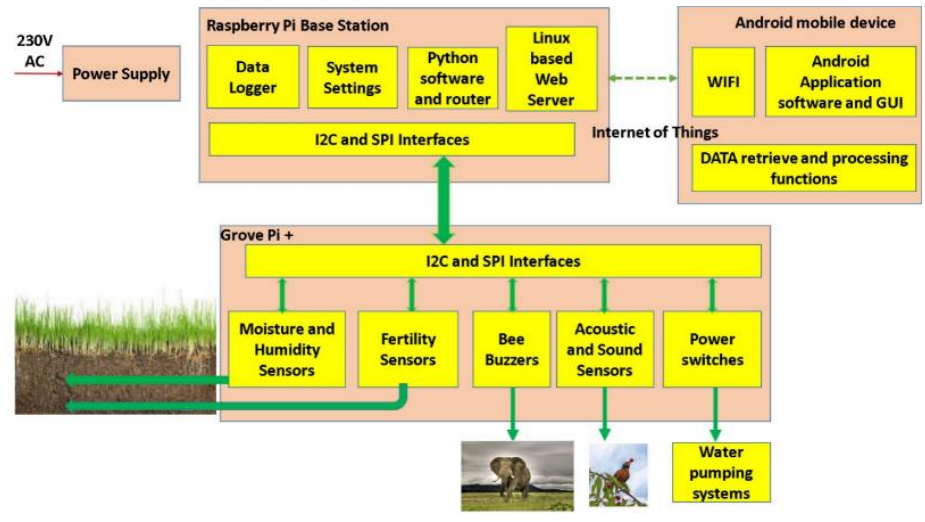

Figure 1. Functional block diagram

\subsection{Features}

- Soil moisture and humidity sensors measure the moisture levels of the soil

- Sound sensors sense the noises made by certain birds and animals

- Ion-selective field effect transistors measure the Soil PH levels and fertility levels

- Power switches take care of switching on and off the watering systems

- Acoustic sensors and Beehive simulators provide information about Elephants and other animal intrusion and keep them away

The agricultural automation featires stated above can be achieved by using Wireless Sensors and the Internet of Things and developing the hardware and software systems involved. Below is a brief description of the hardware and software systems used for building this Low cost Agricultural Automation deviceAGRIPI.

- RASPBERRY PI microcontroller board and peripherals

- GROVE PI+ board interfacing sensor devices to the RASPBERRY PI microcontroller

- Grove Wireless sensor network setup for moisture and humidity sensors, acoustic sensors, buzzers, IR camera and Ion-selective field effect transistors

- Android/IOS installed mobile for running the mobile application software

- Web server for storing the data and downloading on to a mobile device

- Network powered switches and breadboard wires

- Python Software architecture and development for RASPBERRY PI bring up and functioning

- Android/IOS application software architecture and development

- Solar panel to provide Input power supply, Ethernet and USB cables

\section{PROCEDURE SPECIFICALLY DESIGNED}

The input sensor information is collected on to a base station processor and processed and uploaded on to the internet through Internet of Things. This information is received on an Android/IOS based mobile device with an application developed for Android/IOS devices that displays the required information and allows the farmers to monitor and control the agricultural automation parameters with simple Graphical User Interface. AGRIPI automates all monitoring and control farming tasks by providing control from an Android/IOS application software installed on the farmer's mobile device.

The carefully selected sensors for moisture and humidity, buzzer and sound sensors, relays, power switches, light sensors etc. get connected to the AGRIPI base station. The combination of sensors along with the data logger and the base station RASPBERRY PI and GROVE PI+ makes an ideal hardware platform for this agricultural automation project. The software architecture using SPI and I2C interfaces communicates with the sensors and the Android/IOS application software efficiently.

As soon as the device is setup, solar powered battery powers up the device and RASPBERRY PI board and GROVE PI+ boards boot sequence starts and both boards complete the booting sequence using Linux operating system boot image "RASPBIAN". Wireless Sensors sense the agricultural parameters and send these to the data logger using PYTHON scripts. Data logger processes this data and uploads the files to Internet of Things. Mobile device downloads these files from Internet of Things using web servers and Android/IOS application software. The data is displayed in the form of graphs, plots etc. on the mobile device using Android/IOS application" AGRISOFT". Smart easy to use Graphical User Interface (GUI) is 
developed that displays this data in the form of plots hourly, daily, weekly and monthly formats. The Farmer is provided with a set of on/off power buttons for switching on/off the watering systems, bee simulators and other simulated noises for bird and animal control. The RASPBERRY PI and GROVE PI+ boards get the control information back on Internet of Things and start running the required PYTHON scripts for starting the required buzzers, sensors and water pumping system control. The buzzers, sensors and watering systems get power on/off set with timers etc. and do the required automation job.

Software development using Python packages, mobile application development using Linux operating system on the Raspberry PI and GROVE PI+ microcontroller hardware development platform is the work in progress for this research activity.

\subsection{Functioning and Software, Hard ware details of AGRIPI AND AGRISOFT}

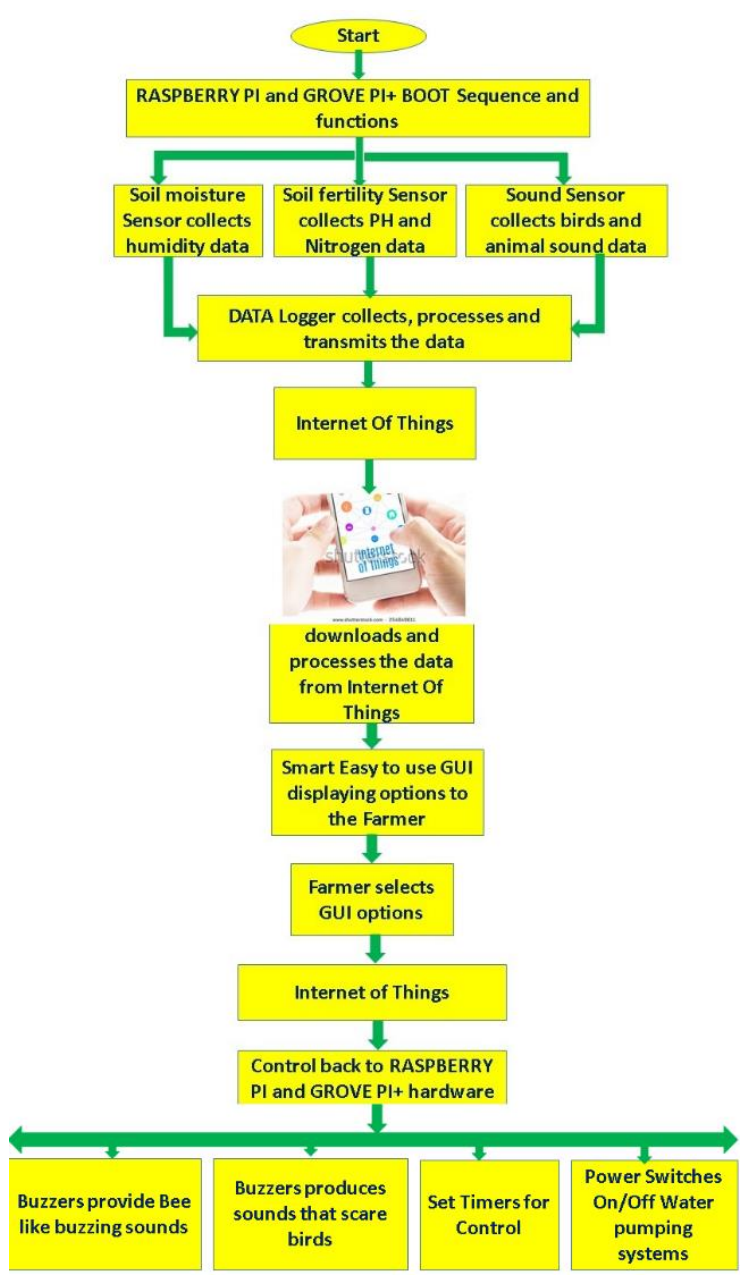

Figure 2. Functional Flowchart

\section{EXISTING RESEARCH METHODS AND STATISTICS}

There are certain products that are available in this area (Reference: [36]), these products address the problems like data logging and analysis, but do not provide an off the shelf solution to farmers that is easy to use, portable and in-expensive.

This research addesses all the issues farmers are facing today like getting the knowledge of Soil moisture and humidity, Seasonal animals or insect attacks, Soil PH levels for fertilizer usage suggestions and organic farming, automation of watering systems using their mobiles. Beehive simulators provide information about Elephants and other animal intrusion and keep them away. The proposed solution also provides features like ease of use, portability and very low cost per device. 
As per the data provided in the article Courtesy www.businessinsider.com [34] "BI Intelligence, Business Insider's premium research service, predicts that IoT device installations in the agriculture world will increase from 30 million in 2015 to 75 million in 2020, for a compound annual growth rate of $20 \%$. The U.S. currently leads the world in IoT smart agriculture, as it produces 7,340 kgs of cereal (e.g. wheat, rice, maize, barley, etc.) per hectare (2.5 acres) of farmland, compared to the global average of $3,851 \mathrm{kgs}$ of cereal per hectare"

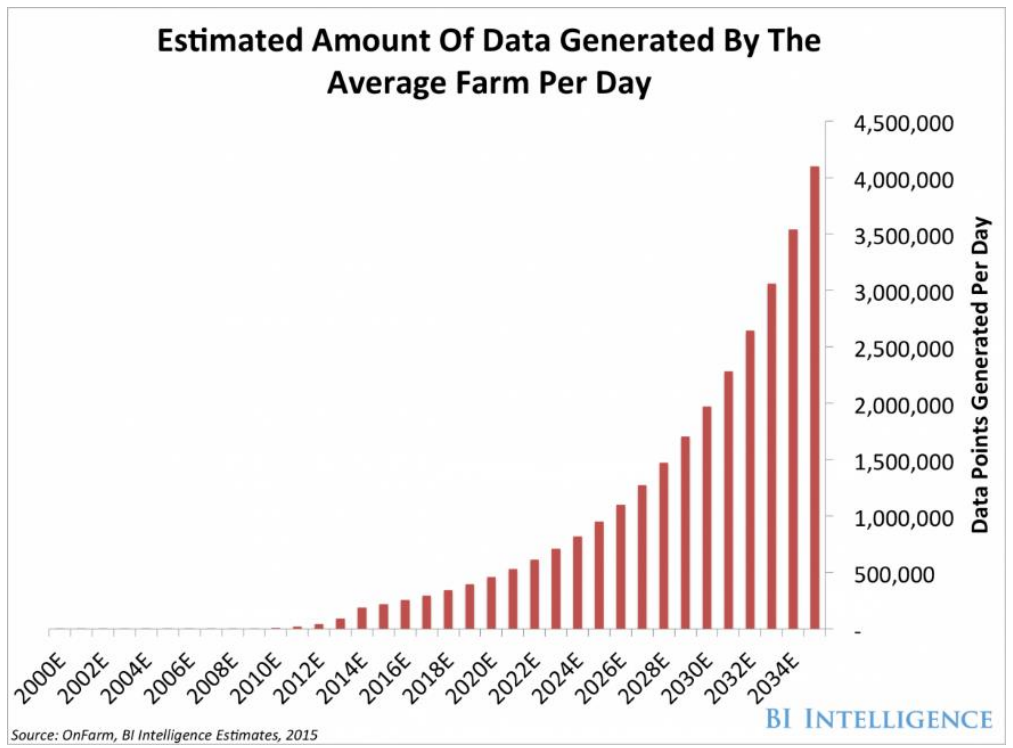

Figure 3. Statistics on the Amount of Data Generated by the Average Farm per Day

This data generated by the Farm, if analyzed and used for futuristic decision making on the farm parameters like watering schedules, plant and seed selection, crop protection from seasonal attacks of animals and insects etc. The hardware and software platforms being developed and tested in this research work will address this problem as the Wireless Sensors provide the data to the data logger and the base station. RASPBERRY PI and GROVE PI+ hardware platform processes this data and captures using the SPI and I2C interfaces to provide the data for analysis and display to the Android/IOS application running on the Mobile device.

\section{EXPECTED RESULTS AND ANALYSIS - AGRIPI}

The design and development of the hardware and software components involved in making the agricultural management "Smart" is the expected result in this research work. Currently the research is in the coding and development phase and this is a review paper for the proposed approach to make Agriculture Smart. The results will be published along with the result and data analysis after the field testing of this device in the Agricultural farms.

In today's world mobiles, have proven to simplify most of our activities. Applying these princples of remote management and portability to the back-bone of World economy - "Agriculture" changes the way the Indian/global farmers perform their farming activities. A system and method is proposed for automation of agricultural activities with the help of these technologies. The system helps the field monitoring activities like water pumping scheduling, plant monitoring, protection from animals and insects etc. to be remotely managed with the help of Mobile sensors and Mobile Apps. A patent is filed for this research and development of software and hardware is in progress.

\subsection{Patent On this Research Work}

This research work is based on an original patent pending invention, by the first author of this paper Mrs Sridevi Navulur, Research scholar, Electronics and Communication Engineering, Koneru lakshmiah University, Guntur Dist) - 522 502, A.P. India. 


\subsection{Title of the patent}

System and Method for Remote Management and Automation of Agricultural Activities through Wireless Sensors and Internet of Things - 3093/CHE/2015, June 2015.

\subsection{Patenting Authority}

Intellectual Property India, Patent Office, Intellectual Property Building.

\section{CONCLUSION}

This research work based on the patent pending invention, a mobile-based sensor automation system for agricultural automation, is aimed to change the way the farmers perform their agricultural activities and help in automating their field monitoring activities like water pumping scheduling, plant monitoring, protection from animals and insects etc. The all electronic mobile-app based system under development is to be affordable, easy to install in the field and delivers results with good level of accuracy and prediction. Future areas of work are completing the software and hardware development, integration, testing and testing the results and accuracy of the system in the agricultural fields.

\section{ACKNOWLEDGEMENTS}

I would like to thank my internal and external research guides, Dr. Chandra Sekhara Sastry sir and Dr. Giri Prasad sir who have provided continuous motivation for this work. I am especially thankful for my Parents, my husband, my sons and all my family members. Farming issues faced by Indian farmers is an inspiration for this research work. The goal of this research is to improve the quality of life for farmers and aid them with automation tools they can easily operate with for their day to day activities as well as long term crop planning.

\section{REFERENCES}

[1] M. Altayeb, et al., "Wireless Sensor Network for Radiation Detection," Indonesian Journal of Electrical Engineering and Informatics (IJEEI), vol/issue: 5(1), 2017

[2] A. Tamizharasi M. E., et al., "Energy Aware Heuristic Approach for Cluster Head Selection in Wireless Sensor," Networks Bulletin of Electrical Engineering and Informatics, vol/issue: 6(1), 2017.

[3] W. Meng, et al., "Recognition Technology for Four Arithmetic Operations," TELKOMNIKA, vol/issue: 15(1), 2017.

[4] K. Haseeb, et al., "Improved Energy Aware Cluster based Data Routing Scheme for WSN," TELKOMNIKA, vol/issue: 14(2), 2016.

[5] Y. Chen and D. Hall, "Reliability Assessment Model for Big Data Structure of Internet of Things," TELKOMNIKA Telecommunication, Computing, Electronics and Control, vol/issue: 14(3A), 2016.

[6] Y. Jingjing, et al., "Family Health Monitoring System Based on the Four Sessions Internet of Things," TELKOMNIKA Telecommunication, Computing, Electronics and Control, vol/issue: 13(1), 2015.

[7] M. Y. Hariyawan, et al., "Wireless Sensor Network for Forest Fire Detection," TELKOMNIKA, vol/issue: 11(3), 2013.

[8] T. Sutikno, et al., "An Improved FPGA Implementation of Direct Torque Control for Induction Machines," IEEE Transactions on Industrial Informatics, vol/issue: 9(3), pp. 1280-1290, 2013.

[9] T. Sutikno, et al., "FPGA Based High Performance Torque and Flux Estimator," International Review of Electrical Engineering, vol/issue: 6(1), pp. 207-214, 2011.

[10] Giselsson T. M., et al., "Seedling Discrimination with Shape Features Derived from a Distance Transform," Sensors, vol. 13, pp. 5585-5602, 2013.

[11] Skierucha W., et al., "A TDR-Based Soil Moisture Monitoring System with Simultaneous Measurement of Soil Temperature and Electrical Conductivity," Sensors, vol. 12, pp. 13545-13566, 2012.

[12] Lofton J., et al., "Estimating Sugarcane Yield Potential Using an In-Season Determination of Normalized Difference Vegetative Index," Sensors, vol. 12, pp. 7529-7547, 2012.

[13] Diago M. P., et al., "Grapevine Yield and Leaf Area Estimation Using Supervised Classification Methodology on RGB Images Taken under Field Conditions," Sensors, vol. 12, pp. 16988-17006, 2012.

[14] J. A. Benedí and R. M. Carpena, "Soil-Water-Solute Process Characterization, an Integrated Approach," CRC Press LLC, Boca Raton, 2005.

[15] Dworak V., et al., "Strategy for the Development of a Smart NDVI Camera System for Outdoor Plant Detection and Agricultural Embedded Systems," Sensors, vol. 13, pp. 1523-1538, 2013.

[16] A. G. Dastidar, et al., "Higher order Markov chain models for monsoon rainfall over West Bengal, India," Indian J. Radio Space Phys., vol. 39, pp. 39-44, 2010.

[17] G. D. Gaskin and J. D. Miller, "Measurement of soil water content using simplified impedance measuring technique," Journal of Agricultural Engineering Research, vol. 63, pp. 153-160, 1996. 
[18] Wilson A. D., "Diverse Applications of Electronic-Nose Technologies in Agriculture and Forestry," Sensors, vol. 13, pp. 2295-2348, 2013.

[19] A. Robinson and M. Cook, "Raspberry Pi Projects Paperback,” Import, 2013.

[20] "Wireless Sensor Network System Design using RASPBERRY PI and Arduino for Environmental Monitoring Applications," Science Direct The 9th International Conference on Future Networks and Communications, 2014.

[21] L. Mainetti, et al., "Evolution of Wireless Sensor Networks towards the Internet of Things: a Survey," University of Salento, Dept. of Innovation Engineering STMicroelectronics Lecce, Italy.

[22] http://ieeexplore.ieee.org/xpls/abs_all.jsp?arnumber=6064380\&tag=1

[23] D. Norris, "The Internet of Things: Do-It-Yourself at Home Projects for Arduino, Raspberry Pi and BeagleBone Black Paperback," Import, 2015.

[24] O. Hersent, et al., "The Internet of Things: Key Applications and Protocols Hardcover,” Import, 2012.

[25] M. Rugueri, "Tor Vergata" Italy, Homayoun Nikookar, Delft University of Technology The Netherland, Internet of Things: Converging Technologies for Smart Environments and Integrated Ecosystems," University of Roma.

[26] G. Kortuem, et al., "Smart objects as building blocks for the Internet of Things," IEEE Internet Computing, vol/issue: 14(1), 2009.

[27] M. Zorzi, et al., "From today's INTRAnet of things to a future Internet of Things: a wireless- and mobility-related view," IEEE Wireless Communications, vol/issue: 17(6), 2010.

[28] J. Vasseur and A. Dunkels: "Interconnecting Smart Objects with IP - The Next Internet," Morgan Kaufmann, 2010.

[29] N. Zang, et al., "Mashups: who? What? Why?" Proceedings of CHI, Florence, Italy, 2008.

[30] M. Kovatsch, et al., "Embedding Internet Technology for Home Automation," Proceedings of ETFA, Bilbao, Spain, 2010.

[31] G. M Lee and N. Crespi, "The Internet of Things - Challenge for a New Architecture from Problems," IETF Internet Architecture Board, Interconnecting Smart Objects with the Internet Workshop, Prague, Czech Republic, 2011

[32] K. R"Omer and F. Mattern, "The Design Space of Wireless Sensor Networks," Wireless Communications, IEEE, vol/issue: 11(6), 2004.

[33] D. Culler, et al., "Guest Editors' Introduction: Overview of Sensor Networks," vol/issue: 37(8), 2004.

[34] A. Meola, "Why IoT, big data \& smart farming are the future of agriculture," 2016.

[35] K. Martinez, et al., "Glacsweb: a Sensor Network for Hostile Environments," in Proceedings of the Sensor and Ad Hoc Communications and Networks Conference (SECON), 2004.

[36] https://www.thingworx.com/ecosystem/markets/smart-connected-systems/smart-agriculture/

\section{BIOGRAPHIES OF AUTHORS}

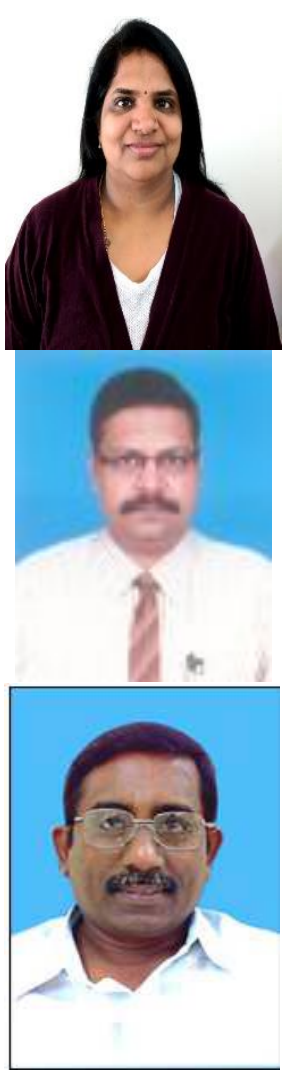

Mrs Sridevi Navulur has over 15 years of Industry experience with a demonstrated history of working in the wireless industry. Skilled in Semiconductors, VLSI Design, Internet of Things, Wireless Communiactions and Embedded System Design. Strong Engineering Professional working towards her Doctorate of Philosophy (Ph.D.) focused in Smart appliances and automation using Wireless Sensors and Internet of things from KL University. She is a Life Member of I.E.T.E. Contact Details: 2508, Windsor Ridge Drive, Westborough, MA-01581, USA.

Dr. A.S.C.S. SASTRY, Professor and Head of the Department is an academician and a researcher who has worked in various capacities in a career spanning over 15 years. He obtained his B.E. (Electronics) from Pune University, Pune, Maharashtra, M.Tech. (ECE) from COE, Kakinada and PhD from JNT University, Hyderabad in the area of Pattern recognition (Image Processing) in the year 2008. He has 30 publications in International and National Journals/Conferences to his credit. He is a Life Member of I.E.T.E and I.S.T.E. His research / interested areas include Embedded System Design, Image and Signal Processing Applications and Real Time Systems. Contact Details: C-112, Computer Block, KL University.

Dr. M/N. Giri Prasad has an experience of over 27 years in Teaching and Research and has published over 72 Papers in several National and International Journals and Conferences. His Research areas include Bio-Medical Signal Processing, Image Processing, Microcontrollers, Communications and Instrumentation. Contact Details: Address: Department of ECE, JNATUACE, Anantapuramu. 